\section{COMMENTARY \\ What American urban secondary schools could be: an international perspective}

American

urban

secondary

schools

\section{Not much has changed}

Back in the spring of 2005, as a first-year doctoral student at the University of Minnesota, I participated in an enrichment program for foreign Fulbright scholars pursuing graduate degrees in US universities. The program was held in New Orleans just a few months before Hurricane Katrina struck Louisiana. More than the enrichment agenda, I enjoyed the mild spring weather of New Orleans and deep cultural flavors imbued in the city. On the last day of the program, the participants visited a local high school in New Orleans. I still remember the moment that I walked through the entrance gate of the high school, because I encountered a dark side of the urban schooling system in America: I saw a police officer with a gun and police car just in front of the main building. "Oh my goodness, a police officer with a gun in school!" I was thinking inside. One may dismiss my experience as just a cultural shock. But I think it is more than culture shock; it is evidence of a systemic problem persistently facing US urban schools. My intention is not to debate the pros and cons of law enforcement officers in US schools[1]. Rather what I wish to point out is that things have become worse since the first school resource officer was assigned to a school in the 1950s. School violence issues have escalated, and other major dysfunctions appear to be perpetuating across many secondary schools in the US. This is evidenced in this JEA special edition, titled "Understanding and improving urban secondary schools: new perspectives." For example, Roozbeh Shirazi depicts the issue of segregation within a school through the eyes of school staff:

[...] what's happening even in the lunchroom [...] every time I went down there looking for a student, I'm like, oh, look towards the black tables or the white tables or whatever because very rarely are they, are they intermingling and it's really disappointing.

Despite the Brown vs Board decision of 1954, black-white racial segregation between schools has continuously taken place in parallel with the racial segregation between urban and suburban areas (Orfield and Lee, 2006). Furthermore, racial segregation within an urban school, illustrated in Shirazi's article in this issue, has been consolidated and complicated with the influx of new immigrants, including refugees. The findings presented by Shirazi resonate with Stacey Lee's (2004) observation 14 years ago from an urban high school in Wisconsin:

As a relative newcomer to the United States [...] Cha [Hmong ESL student] occupies the sidelines in the cafeteria, the halls, and classrooms [...] Cha has a small circle of Hmong friends that include his girlfriend and two other boys. Significantly, his friends are all relative newcomers to the United States [...] Cha regularly eats lunch with this same group of friends and laughs and talks quietly [...] (p. 21).

Within-school segregation should not be trivialized as students' voluntary self-segregating behaviors. Such behaviors appear to be consequences of multiple forms of disadvantage (e.g. lack of parental involvement, culturally-insensitive curricula, limited English proficiency, institutionalized racism, peer pressure, low SES, school poverty, crime). Within this multi-layered disadvantage, minoritized students' self-segregation within a school seems to be the last resort, because they have no other

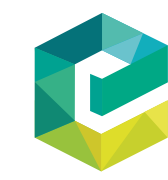

Journal of Educational Administration Administration
Vol. 56 No. 5,2018 pp. $463-472$ (c) Emerald Publishing Limited DOI 10.1108/JEA-08-2018-172 
JEA

56,5

464

options (cf. Lee et al., 2017). In addition, drawing on Stacey Lee's observation and Roozbeh Shirazi's findings, it can be said that not much has changed in US urban schooling scenes. One may treat the similar findings of the two studies in different temporal points as anecdotal evidence for within-school segregation.

Then, how about the issue of gun violence at school? Is it right to dismiss it as an anecdotal and intermittent issue? Notably, "more than 187,000 students have been exposed to gun violence at school since Columbine" (The Washington Post, 2018). Amid this terrifying situation, the US president Donald Trump's solution (i.e. arming teachers) is terrible and even treacherous. This can be neither a fundamental solution nor a quick fix. The seven articles in the JEA special issue provide new perspectives and possibilities, as in the title of the special edition, for us to approach and address the persistent problems facing urban schools in the US In the following sections, I detail how the unparalleled set of research papers in this special issue advances new perspectives of urban education.

\section{Student voice for deeper change}

Let me start by sharing a story about Charlie Munger, the well-known American investor, who is Vice Chairman of Berkshire Hathaway. He was at a local shop to buy a fishing lure. He was holding sparkling plastic fishing tackle and asked the shop owner "My God, they're pink and green. Do fish really take these lures?" The shop owner replied "Mister, I don't sell to fish" (Griffin, 2015, p. 17). This episode provides an analogy to the problems embedded in reform polices associated with externally imposed accountability measures. A sparkling object - such as turnaround reform - is viewed as a quick-fix measure for improving student learning and may, therefore, be attractive to some stakeholders such as parents and policy makers (customers for the fishing lures). However, turnaround reform (the shiny lure) is, in essence, not appealing to students (i.e. fish). In other words, it often seems that stakeholders (e.g. policy makers, parents, and researchers) involved in education reform may have been more attentive to a sparkling tool than its genuine potential for achieving what they want. The most important stakeholder has been relatively overlooked.

"Student voice in secondary schools: The possibility for deeper change," by Dana Mitra sheds light on how student voice can make a difference in school change. While accumulating reform initiatives, described by Sebring and Bryk (2000) as a "Christmas tree" approach, can hit the target, they often miss the potential for deeper and more lasting change because of the dearth of attention to student experiences. Mitra clearly shows how we can tap into the potential of student voice for deeper changes in school. She illuminates that when "student voice efforts can lead to increased interest in institutionalizing student input into the decision-making process" beyond tokenistic or symbolic student participation in implementation efforts, students become change agents in school and can bring authentic school changes.

I absolutely agree with Mitra's stance. Furthermore, I believe that institutionalizing student voice in the routine of school life as well as reform processes at a school level is much needed for secondary schools in East Asia. While there would be a variation, secondary school students in East Asia are put under intense pressure in competitive exam-oriented schooling systems. Yet students have been pushed to remain silent about what they deeply care about in their learning environment, such as relationships, happiness, friendship and well-being. To me, student voice is something like the "invisible gorilla" (Chabris and Simons, 2010)[2]. Like the invisible gorilla experiments, we often fail to recognize the importance of student voice even though it has always been around and within our schools as possible pathways to address complex problems facing many schools. This is because we have emphasized other solutions that rarely pay any attention to student voice. In this regard, Mitra's research contributes greatly to unleashing the hidden resources to our efforts to deepen the changes of urban secondary schools. 


\section{The age of identify, engagement and well-being}

In his presidential address at the 2018 International Congress for School Effectiveness and Improvement, Andy Hargreaves asserted that we are departing from the age of achievement to "the age of identity, engagement and well-being" (Hargreaves, 2018). "Socio-political belonging and the identity of transnational students" by Roozbeh Shirazi in this special issue is well positioned to address Hargreaves's proposition. Specifically, Shirazi addresses student voice as a core part of socio-political belonging and identity by questioning "which voices count, and how they come to have value." In this regard, Shirazi echoes Mitra's stance on student voice for deeper school change. At the same time, it is important to pay attention to the role of institutional agents in students' formation of socio-political belonging, depicted in Shirazi's article. Shirazi fleshes out the contrasting roles of institutional agents in legitimating student voice by illuminating the lived-experience of Somali Muslim students in Light Falls High School in a Midwest urban area. Three institutional agents are featured in Shirazi's study - i.e., Ms. Sharp, the mental health specialist who also worked with the Muslim Student Association (MSA) as a faculty adviser, an unnamed staff member and Ms. Bernard, the principal.

When the principal notified Ms. Sharp and MSA students that MSA would not be permitted to meet in the school because it is a religious group, Ms. Sharp was the only institutional agent who went against the principal's decision by supporting MSA students to keep their meetings and activities in the school. Drawing on my own research, which explored an Afro-centric urban secondary school in a Midwest urban area, I also identified such supportive institutional agents who play a key role in guiding refugee students to the pathways of successful school life (Lee and Madyun, 2012; Lee et al., 2014). More importantly, as minoritized adolescents built trust with supportive institutional agents, they exhibited more help-seeking behaviors with institutional agents in order to cope with structural forces impeding their healthy socialization (Lee, 2009; Lee and Madyun, 2012).

The principal's decision to close the MSA is seen as "racialized policing," given her comment, "in America, we have separation of church and state." To me, the principal's comment sounds quite similar to the Trump Administration's detention policy of separating children and parents who illegally enter the USA. That is, the principal's comment sounds as if Trump would have said, "in America, we have separation of children and parents if you are illegal immigrants." While I write this commentary paper today, Trump announced that the government retreats the harsh detention policy at the borders under enormous political pressure by ordinary people's collective protests in the USA against the cruel and inhumane detention policy. Like ordinary American people did, the students at Light Falls High School continued advocating for the MSA and eventually the decision of the principal was overruled by the superintendent. This amazing story evidences that a school is a miniature of the whole society. As Kathryn Riley says in her commentary paper, the story further evidences that "protest shapes possibilities."

There is another lesson about institutional agents that we can take from Shirazi's article, which reminds me of Stanton-Salazar's (2001) comment about how a lack of cultural sensitivity of institutional agents with good intention can be problematic. An unnamed respondent was reported as saying to a student, "I've watched other students and I know you are struggling with your hijab. You know, it's ok to do what you want [...]. It's alright. You know, in fact here's my number, if you want to take the next step, let me know [...]" The student was, not surprisingly, offended. Notably, although many institutional agents attempt to help ethnic minority students, it is rare that they develop mentor-mentee relationships. On the one hand, students' low trust of social ties with institutional agents, especially those who are from different racial-ethnic groups, may be legitimate (Stanton-Salazar, 2001). As in this case, the accumulated experience of cultural insensitivity by institutional agents can create barriers to future efforts to help. 
JEA

56,5

\section{Walking the talk}

"Talk it (racism) out: Race talk and organizational learning" by Decoteau Irby and Shannon Clark demonstrates that the use of race-specific language is essential to school improvement particularly in demographically changing school contexts. This is because race talk can unleash teachers' vacillation and reluctance to talk explicitly about racial issues at school. I am convinced by Irby and Clark's argument that "using race-specific language makes problem framing more concrete and specific" than using race-mute language. Their argument makes me rethink the case of Singapore, which has been applauded for its racial harmony for decades by neighboring Asian countries. Research suggests that there are several reasons for Singapore's successful racial harmony such as the government's policy efforts for social integration through public housing with racial quotas, equal education opportunities and mandatory national service (cf. Chew, 2018). Indeed, Singaporeans tend not to talk about racial issues publicly. Neither do researchers in Singapore. Chew's (2018) comprehensive search through Google Scholar found only 13 studies (mostly qualitative, narrative studies) on racism in Singapore. Is all this because Singapore is a matured multicultural society?

A recent large-scale survey of 2,000 Singaporeans (Mathews, 2016) tells another story. The survey reveals that two thirds of Singaporeans are reluctant to discuss racism or racial issues because such race talk would cause unnecessary tension. Even almost half to two thirds of them are not supportive of publicly-available information that could display racial disparities in social issues such as educational attainment and crime (Mathews, 2016 cited in Chew, 2018). A recent comment of Janil Puthucheary (the Senior Minister of State in the Ministry of Communications and Information and the Ministry of Education) resonates with the survey finding: "[...] people are hesitant and afraid to discuss race relations because of the fear of being seen as racist. They are also afraid of offending other races [...]" (The Straits Times, 2016). On another occasion, he also commented "Do we shy away and pretend this problem doesn't exist? Or do we accept the fact that we should work on this together? [...] how to engage, how to talk about it [racial issues], and how to learn is actually a very positive result" (The Straits Times, 2017).

As I noted earlier, school is a miniature of the whole society. As Irby and Clark stressed the importance of race talk at school, which echoes the Singaporean Minister's comment on the need for race talk in the whole society, using race-specific language with open mind is the first step towards resolution of racial issues at school and in society. This is the pathway to avoid the pitfall that frames racism as "out of my control" and reduces systemic racial problems to personal remedies such as "being nice" as highlighted in Irby and Clark's article.

\section{Trust in emotional ecology}

Peter Demerath's article, titled "The emotional ecology of school improvement culture," represents a crosscutting theme of the three articles commented above - i.e., strengthening diverse agents through voice, talk, conversation and engagement. At the same time, Demerath focuses more on delving deeply into how teachers and school leaders talk about their "emotions." He illuminates a set of interlocking feedback loops (i.e. empathy, optimism, motivation, confidence, trust) that create and circulate emotionally charged meanings that, in turn, shape school improvement culture. Given the limited space for this commentary, I wish to focus on one of the feedback loops - i.e., trust in shared leadership - because "trust" is a core part of any form and function of school organizational relations (Bryk and Schneider, 2004). Demerath shows how relational trust can be fostered through shared leadership, which is well illustrated in the following observation in a secondary public school in a socio-economically disadvantaged urban area:

Indeed, during a meeting of the school's "College Readiness" group in October, 2012, the principal came in for the last 15 minutes and sat down at the end of the table. When he entered one of the 
teachers on the committee said with a smile, "Uh oh, look who's here." The principal smiled and said, "Just keep going." The meeting continued and the principal was silent throughout. When the meeting concluded he simply got up, patted the teacher who had made the initial comment on the back, and said, "Keep it up."

As Demerath notes, the principal's silence is absolute endorsement of teachers' leadership, implying his confidence and trust on teachers' work and expertise. Given that teachers are entrusted and empowered, they would be more likely to regulate and release their emotions in a positive form (e.g. empathy, optimism, confidence). In other words, it seems that relational trust among school members functions as a "pressure valve" for teachers to regulate and release work-related emotions in a way to cultivate school improvement culture.

The remaining question is, how we can generate relational trust at school? Demerath's answer is simple but significant: "come together, talk, and listen. Conversation is slow [...] [but] have to sit and listen again and again to conversations [...]" This answer powerfully reminds me of a statement from Simon Sinek's (2014) book, titled Leaders eat last: "Trust is not formed through a screen, it is formed across a table. It takes a handshake to bind humans [...] and no technology yet can replace that. There is no such thing as virtual trust” (p. 111).

\section{Turnaround is rarely pure and never simple}

Ann Ishimaru's article, "Re-imagining turnaround: Family and community leadership in school improvement for educational justice," brilliantly complements Mitra's and Shirazi's articles. While the latter two articles revisit the relatively overlooked agent of change inside the school for school improvement (i.e. minoritized students), Ishimaru finds other neglected agents of change outside the school - i.e., families (parents) and community leaders in a low SES community. Ishimaru also places the potential of family and community as change agents in the challenging context of neoliberal education reforms.

She proposes "educational justice" referring to "the community-determined educational aims that move beyond test-score based assessments of effectiveness" by problematizing the term of "equity" used in the neoliberal accountability context because the term "has been taken up in practice as a narrow aim of achieving test-score outcomes that do not vary by race [...]" We know that this kind of a narrow definition of equity is widely used by policy makers in the process of policy formulation. Notably, OECD has actively disseminated narrow testing metrics as an equity measure through its policy infrastructure (e.g. PISA reports). In addition, pseudo-scientific reports generated by think tanks such as McKinsey \& Company and the Grattan Institute have reinforced the influence of OECD on global education policy discourses. Policy makers seem to not just buy the shiny fishing lure of narrow standardized test metrics as a measure of equity, but also formulate educational policy based on those numbers in the metrics. This trend is particularly salient in Anglo-Saxon and East Asian countries. We all know that when Shanghai was ranked at number one in the 2009 PISA, U.S. Education Secretary Arne Duncan said, "This is an absolute wake-up call for America" (NBC News, 2010). Three years later, the former federal Education Minister Christopher Pyne described Australia's position in the PISA rankings in 2012 as "a serious wake-up call" for the education system (ABC News, 2013). The former UK Education Secretary Michael Gove's perspective is notable: he called Andreas Schleicher, the OECD architect of PISA, "the most important man in English education" (Gove, 2013).

In this regard, in the game of international student achievement comparisons, the winner is not the low-income or minority student or their parents and communities. There are several problems in using narrowly defined equity. First, as Ishimaru's article implies, it confines the boundary of our "aim talk" of education (see also Noddings, 2003). For example, if teacher practices and school leadership are only assessed by test scores, 
JEA

56,5

the contributions of excellent teachers and leaders whose work improves student noncognitive outcomes (such as well-being) are invisible.

A second problem is that narrowly defined equity ignores the importance of local contexts, an issue highlighted by Ishimaru's paper. In a recent PISA report (OECD, 2012), for example, South Korea is categorized as a highly equitable system because of the relatively small variance in PISA scores explained by family SES and the narrow gap between the scores of the top 10 percent and the bottom 10 percent. However, this is mainly because almost every family in Korea invests family resources on kids' education regardless of their SES. Low SES families spend a substantial proportion of household income for private tutoring (cf. Choi and Choi, 2016), which is why the gap in PISA scores between the top 10 percent and the bottom 10 percent in South Korea is very narrow. Furthermore, although the score gap is narrow, high- and low-income students go to different universities, which significantly affects their socio-economic future because of the role of Korean universities in socio-economic reproduction (Lee, 2018; Seth, 2002).

Third, even when it makes sense to use narrow measures of equity in a specific context, the way OECD presents equity can mislead our discussions of school improvement. For example, variation in testing scores explained by family SES in East Asian societies is relatively smaller than other countries, so they are regarded as equitable schooling systems. However, equitable schooling systems can be better measured by the moderating effect of school quality on the direct effect of family SES on educational outcomes. For example, if schools can significantly reduce the negative SES effects on educational outcomes, then it can be said that they are more equitable. Unfortunately, OECD reports do not reflect this aspect.

Ishimaru's article shows how we can possibly pave the new pathway towards more authentic equity-based education reforms. Like other authors in this JEA special edition, she pays special attention to the "voice and talk" of parent and community members as leaders who can reshape the process of school turnaround. Let me conclude my comment on Ishimaru's inspiring study by using Oscar Wilde's quotation: "The truth is rarely pure and never simple." I would say, "Turnaround is rarely pure and never simple."

\section{A missing link: culturally responsive instructional leadership}

"Humanizing school communities of practice: Culturally responsive leadership in the shaping curriculum and instruction," by Stefanie Marshall and Muhammad Khalifa, explores an important but under-researched area in the school leadership literature - i.e., linking instructional leadership to culturally responsive leadership. As Marshall and Khalifa correctly point out, the two types of school leadership are dualistically described in the existing literature. Considering possible theoretical and empirical interfaces between instructional leadership and culturally responsive leadership, cross-fertilization between the two is much needed.

Instructional leadership has been integral to education reforms, given its strong association with student achievement (cf. Hallinger, 2005; Robinson et al., 2008). In other words, the need for instructional leadership in school improvement has been reinforced by highly rationalized global education discourses, emphasizing accountability for student learning within the "chain of command." In many countries, instructional leadership is regarded as a policy instrument for school improvement. In this regard, instructional leadership can be called "global syntax" in making sense of what and how leadership practices ought to be embodied in school improvement.

At the same time, the local interpretation of instructional leadership across different schools and schooling systems - which can be called "local semantics" - appears to result in varying (or even contrasting) effects of instructional leadership on student learning outcomes. Research shows that there are variations in terms of how instructional leadership 
is interpreted and enacted across different organizational and broader cultural contexts (cf. Lee and Hallinger, 2012) and thereby discrepant effects of instructional leadership on student achievement (Lee et al., 2012; Walker and Ko, 2011)[3]. This seems to be because instructional leadership is a multidimensional construct (Hallinger, 2005; Hallinger and Murphy, 1985; OECD, 2009) whereas different dimensions of instructional leadership are either articulated or attenuated in the process of the local semantics (Lee et al., 2012; Lee and Dimmock, 1999), depending on local school contexts or broader societal cultures. We may speculate that typical instructional leadership practices - e.g. supervision of instruction such as "actions to directly supervise teachers' instruction and learning outcomes" (OECD, 2009 , p. 195) - may not work properly at schools with changing demographics, including students with ethnically and culturally diverse backgrounds. It should also be noted that in some East Asian school systems, principals' instructional supervision, monitoring and observation in class may be interpreted as intrusion on teachers' autonomy because teachers' instruction in class is traditionally seen as the territory of teachers' control (cf. Lee and Kim, 2016).

To enact instructional leadership on the ground more effectively, I think that culturally responsive leadership needs to be infused in instructional leadership. This is since culturally responsive leadership places more emphasis on context-specific leadership practices by reflecting on diverse cultures and local school communities to create more inclusive school environments for all students. Empirical investigations on such infusion and interdependence between instructional leadership and culturally responsive leadership are richly offered in Marshall and Khalifa's study.

\section{Bricks of trust for the "broken bridges"}

The longitudinal social network analysis of school leaders in an urban school district by Yi-Hwa Liou and Alan Daly (Broken bridges: A social network perspective on urban school leadership) presents an important but surprising finding: "over time high school principals have decreasing access to social capital and are typically occupying peripheral positions in the social network. The high school principals' perception of innovative climate across the district decreases over time."

What was happening to the high school principals? Why were they losing social ties and becoming more isolated over time? Although the quantitative research, given its nature, does not tell us a deep story about the questions, we can find an important puzzle piece of the full picture from the network analysis. The participants in the study were asked to respond to the following question: "Who do you turn to for advice about implementing the Common Core State Standards?" Note that this is a question about "advice" network, which is significantly influenced by "trust" among network actors (cf. Daly et al., 2014). More often than not, principals are tempted to manage things "in-house rather than constantly asking for support and advice [...][that] may risk sending signals of [their] weak leadership" to the central office (Page, 2014, pp. 60-61). In a school district environment where trust between principals and central office administrators is not established, such self-helping or self-managing behaviors would be more salient. The paucity (or absence) of trust among the leaders in the case school district of Liou and Daly's study could be indirectly gauged in the following finding: "The coupling of reduced reciprocated ties [i.e. mutually connected ties in seeking advice] and reported perception of the [innovate] climate becoming less open to risk taking may also inhibit the formation of ties [of the high school principals]." Drawing on this finding, I speculate that the "increased isolation and reduced reciprocated ties" of the high school principals are because of the lack of trust. This may be rooted in a complex interplay between factors such as intention not to disclose low confidence in leadership, pressure to impress central 
JEA

56,5

office administrators, and competitive school district environments as a quasi-market (cf. Page, 2014). Indeed, this phenomenon is also observed in Australia:

Are principals having the conversations they need? So how do school systems support the work of Australian school principals and create opportunities for authentic conversations? And how do school principals (at different stages of their careers) make use of that support? In most school systems, supervision and support for school principals is provided by the same person - and many principals have indicated that they are always conscious of this when they meet with their supervisors and senior managers. Principals' associations and education unions and individual principals have also commented that principals' meetings may not always be good forums for professional or personal disclosure. Who do principals prefer to turn to for advice and support when they are struggling with leadership issues? (Page, 2016, p. 1, italics added)

To rebuild the "broken bridges" as in the title of Liou and Daly's article, we should note that relationships between school leaders and central office administrators are not always conducive to authentic and open conversations. I, thus, think that the bricks of trust matter for rebuilding the broken bridges.

\section{Looking forward to the new directions}

My unexpected encounter of the police officer in a New Orleans secondary school in 2005 is no longer news to Koreans. Since 2012, the second largest metropolitan school district in Korea has allocated law enforcement officers to public schools. The former US president Obama praised the Korean schooling system several times. One of the reasons was its almost perfect high school completion rate as opposed to the persistent problem of high school dropout rate in the US But if we visit typical Korean high school classrooms, it is not difficult to find students sleeping during teachers' instruction. This kind of classroom scene is normalized for many Koreans. Even most teachers do not intervene to wake those sleeping students during class hours. Notably, these sleeping students are not different from dropouts in US high schools. Even though they are physically in schools, they have nothing to do with learning and education. They are, in essence, dropouts because they give up their learning and their teachers give up on them. The Korean secondary schooling system is regarded as highly effective, highly efficient, and highly equitable, measured by OECD PISA (cf. Jensen, 2012). But deep inside the system, I see many commonalities between the so-called high-performing system and the US secondary schooling system.

How can we change? The seven articles in this stellar edition shed light on possible pathways that need to be taken. Thus, the challenge is to build on and extend a deeper understanding of voice, context, and the meaning and measure of equity in looking at urban secondary schools around the world. As I noted at the beginning of this commentary and have reiterated throughout, there are no quick fixes, but this issue provides additional insights to begin to shift both local and national conversations.

Moosung Lee

University of Canberra, Canberra, Australia

\section{Notes}

1. See Kathleen Nolan's (2011) Police in the hallways for the debates.

2. The invisible gorilla is a cognitive psychology phenomenon that when people are solely or too much focused on one particular thing, they easily overlook something important and obvious, taking place simultaneously.

3. Notably, Robinson et al's (2008) meta-analysis suggests that although the effect size of instructional leadership on student achievement is the highest among other types of leadership, there is a variation in the effect size of instructional leadership, even including some negative effects, depending on school contexts. 


\section{References}

American

ABC News (2013), "Christopher Pyne says PISA results are 'serious wake-up call' for Australian Education System”, December 4, available at: www.abc.net.au/news/2013-12-04/christopherpyne-says-pisa-results-are-serious-wake-up-call/5133838 (accessed July 23, 2015).

Bryk, A. and Schneider, B. (2004), Trust in Schools: A Core Resource for Improvement, Russel Sage Foundation, New York, NY.

Chabris, C. and Simons, D. (2010), The Invisible Gorilla: How Our Intuitions Deceive Us, Crown Publishing, New York, NY.

Chew, P. (2018), "Racism in Singapore: a review and recommendations for future research", Journal of Pacific Rim Psychology, Vol. 10 No. 5, pp. 1-8.

Choi, H. and Choi, A. (2016), "Regulating private tutoring consumption in Korea: lessons from another failure", International Journal of Educational Development, Vol. 45 No. 1, pp. 144-156.

Daly, A., Liou, Y.H. and Moolenaar, N. (2014), "The principal connection: trust and innovative climate in a network of reform”, in Van Maele, D., Forsyth, P. and Van Houtte, M. (Eds), Trust and School Life, Springer, Dordrecht, pp. 285-311.

Gove, M. (2013), “'The Independent' on education reforms”, available at: www.gov.uk/government/ speeches/michael-gove-article-in-the-independent-on-education-reforms (accessed July 22, 2015).

Griffin, T. (2015), Charlie Munger: The Complete Investor, Columbia Business School Publishing, New York, NY.

Hallinger, P. (2005), "Instructional leadership and the school principal: a passing fancy that refuses to fade away", Leadership and Policy in Schools, Vol. 4 No. 3, pp. 221-239.

Hallinger, P. and Murphy, J. (1985), "Assessing the instructional leadership behavior of principals", Elementary School Journal, Vol. 86 No. 2, pp. 217-248.

Hargreaves, A. (2018), "Purpose, professionalism, leadership and change", unpublished address, International Congress for School Effectiveness and School Improvement, Singapore, January 9.

Jensen, B. (2012), Catching up: Learning from the Best School Systems in East Asia, The Grattan Institute, Melbourne, available at: https://grattan.edu.au/report/catching-up-learning-from-thebest-school-systems-in-east-asia/ (accessed June 24, 2018).

Lee, J.C. and Dimmock, C. (1999), "Curriculum leadership and management in secondary schools: a Hong Kong case”, School Leadership \& Management, Vol. 19 No. 4, pp. 455-481.

Lee, M. (2009), "Decoding effects of micro social contexts on the academic achievement of immigrant adolescents from the poor working-class: peers, institutional agents, and school contexts", unpublished doctoral dissertation, University of Minnesota, Twin Cities, MN.

Lee, M. (2018), "A critical perspective of think tank reports' influence on measuring and comparing the outcomes of schooling systems", paper presented at the annual meeting of the International Congress for School Effectiveness and Improvement, NIE, Singapore, January 10.

Lee, M. and Hallinger, P. (2012), "National contexts influencing principals' time use and allocation: economic development, societal culture, and educational system", School Effectiveness and School Improvement, Vol. 23 No. 4, pp. 461-482.

Lee, M. and Kim, J. (2016), "The emerging landscape of school-based professional learning communities (PLCs) in South Korean schools", Asia Pacific Journal of Education, Vol. 36 No. 2, pp. 266-284.

Lee, M. and Madyun, N. (2012), "Deciphering Somali immigrant adolescents' navigation and interpretation of resources embedded in social relationships", in Bekerman, Z. and Geisen, T. (Eds), International Handbook of Migration, Minorities, and Education, Springer, Dordrecht, pp. 659-676.

Lee, M., Lam, B. and Madyun, N. (2017), "Effects of different-race exposure in school and neighbourhood on reading achievement of Hmong students in the U.S.", Urban Education, Vol. 52 No. 10, pp. 1255-1283.

Lee, M., Madyun, N., Lam, B. and Jumale, M. (2014), "School contexts and acting white”, Schools: Studies in Education, Vol. 11 No. 1, pp. 122-155. 
JEA

56,5

Lee, M., Walker, A. and Chui, Y.L. (2012), "Contrasting effects of instructional leadership practices on student learning in a high accountability context", Journal of Educational Administration, Vol. 50 No. 5, pp. 586-611.

Lee, S.J. (2004), "Hmong American masculinities: creating new identities in the United States", in Way, N. and Chu, J. (Eds), Adolescent Boys: Exploring Diverse Cultures of Boyhood, New York University Press, New York, pp. 13-30.

Mathews, M. (2016), Channel News Asia-Institute of Policy Studies (CNA-IPS) Survey on Race Relations, Institute of Policy Studies, National University of Singapore, Singapore.

NBC News (2010), “'Wake-up call': US students trail global leaders”, December 7, available at: www. nbcnews.com/id/40544897/ns/us_news-life/t/wake-up-call-us-students-trail-global-leaders/\#. WzCFg_kzaUk (accessed July 22, 2015).

Noddings, N. (2003), Happiness and Education, Cambridge University Press, New York, NY.

Nolan, K. (2011), Police in the Hallways: Discipline in an Urban High School, University of Minnesota Press, MN.

OECD (2012), PISA 2012 Results: Excellence through Equity (Volume II), PISA, OECD Publishing, Paris.

OECD (2009), Creating Effective Teaching and Learning Environments: First Results from TALIS, OECD, Paris.

Orfield, G. and Lee, C. (2006), Racial Transformation and the Changing Nature of Segregation, The Civil Rights Project at Harvard University, Cambridge, MA.

Page, C. (2014), "School leaders, school systems and the work of school turnaround", Unpublished manuscript.

Page, C. (2016), “Australian school principals and their school systems - how's it going?”, Unpublished manuscript.

Robinson, V., Lloyd, C. and Rowe, K. (2008), "The impact of leadership on student outcomes: an analysis of the differential effects of leadership types", Educational Administration Quarterly, Vol. 44 No. 5, pp. 635-674.

Sebring, P. and Bryk, A. (2000), "School leadership and the bottom line in Chicago", Phi Delta Kappan, Vol. 81 No. 6, pp. 440-443.

Seth, M. (2002), Education Fever: Society, Politics, and the Pursuit of Schooling in South Korea, University of Hawaii Press, Hawaii.

Sinek, S. (2014), Leaders Eat Last: Why Some Teams Pull Together and Others Don't, Portfolio/Penguin, New York, NY.

Stanton-Salazar, R.D. (2001), Manufacturing Hope and Despair: The School and Kin Support Networks of US-Mexican Youth, Teachers College Press, New York, NY.

The Straits Times (2016), "We need to talk about race issues, says minister", August 12, available at: www.straitstimes.com/singapore/we-need-to-talk-about-race-issues-says-minister (accessed June 23, 2018).

The Straits Times (2017), "Right response to potentially racist remarks can help deepen understanding: Janil Puthucheary", July 19, available at: www.straitstimes.com/singapore/right-response-topotentially-racist-remarks-can-help-deepen-understanding-janil (accessed June 23, 2018).

The Washington Post (2018), "Scarred by school shootings", March 25, available at: www. washingtonpost.com/graphics/2018/local/us-school-shootings-history/?utm_term=.5be2 c94ba4a4 (accessed June 23, 2018).

Walker, A. and Ko, J. (2011), "Principal leadership in an era of accountability: a perspective from the Hong Kong context”, School Leadership \& Management, Vol. 31 No. 4, pp. 369-392. 